PEDAGOGISK FORSINING I SVERIGE Vol. 26 No. 2-3 (2021) ISSN 1401-6788

\title{
NOTAT
}

\section{Om tidskriften Pedagogisk Forskning i Sverige och intellektuell organisering av det pedagogiska kunskapsområdet}

\author{
S verker Lind blad \\ Seniorprofessor, Göteborgs universitet \\ Mats Ekholm \\ Professor emeritus, Karlstads universitet
}

För tjugofem år sedan gavs det första numret av Pedagogisk Forskning i Sverige ut. Ambitionen var att skapa en gemensamt ägd och organiserad tidskrift av och för forskarna inom det pedagogiska kunskapsområdet. Det var alltså ingen särskild grupp eller ansats som skulle utveckla tidskriften utifrån sina särskilda intressen, utan tillkomsten byggde på idén om kollektiva intressen av ett gemensamt forum för vetenskaplig kommunikation och argumentation inom vårt område. En tidskrift baserad på sådana idéer skulle då förhoppningsvis bidra till att utveckla kunskapsutbytet inom området och även forskningsanknytningen av pedagogiska utbildningar. I den här artikeln ska vi därför behandla tillkomsten av tidskriften i relation till organiseringen av det pedagogiska kunskapsområdet samt diskutera hur förutsättningarna för detta har förändrats och vilka utmaningar som vi står inför idag.

Artikeln är uppbyggd på följande sätt: först kommer en inramning genom att ta upp frågor om vetenskapliga normer och om intellektuell organisering inom akademin. Sedan följer en betraktelse över starten av Pedagogisk Forskning i Sverige och hur tidskriften tagits emot. Därefter kommer en skiss över förändringar inom det pedagogiska kunskapsområdet av betydelse för forskningskommunikation och kunskapsorganisering. Artikeln avslutas med några ord om vad dessa förändringar kan betyda för vår tidskrift och vilka 
uppgifter vi står inför framöver. Förhoppningsvis kan den utgöra ett underlag för gemensamma diskussioner om vetenskaplig vettighet och strategisk handling!

\section{INRAMNING: OM NORMER FÖR FORSKNING OCH INTELLEKTUELL ORGANISERING INOM AKADEMIN}

Frågor om vetenskaplig organisering och kommunikation inom samhällsvetenskaperna har hanterats på olika sätt inom vetenskapshistoria i mer allmänna termer (se exempelvis Wagner, Whittrock och Whitley, 1991). Inom det pedagogiska kunskapsområdet och hur det organiseras internationellt finner vi framför allt analyser av anglo-saxiska och kontinentala förhållanden knutna till frågor om disciplinering och organisering. ${ }^{1}$ Vi går här in på starten och betydelsen av Pedagogisk Forskning i Sverige med särskild inriktning vad gäller övergripande normer för vetenskaplig verksamhet och hur denna organiseras.

Inspiration till tillkomsten av tidskriften hämtades bland annat från Robert Mertons arbete med etiska normer för vetenskap, ofta känt under beteckningen CUDOS (Communism, Universalism, Disinterestness, Organized Scepticism)(se Merton, 1973/1942). Vetenskaplig verksamhet ska enligt dessa normer vara gemensamt ägd, arbeta med allmängiltiga frågor och verka för det allmänna bästa, inte vara driven av egna intressen, samt systematiskt ifrågasätta egna och andras argument och hävdanden. Dessa normer ska då också gälla för det pedagogiska kunskapsområdet och den vetenskapliga argumentation som förs där. Hur sådana etiska normer ser ut $\mathrm{i}$ praktiken - vilka mönster av handlingar som observerats - har diskuterats på olika sätt. Exempelvis har olika mot-normer identifierats (Mitroff, 1974). Andra exempel relateras till hur systemet för högre utbildning och forskning har förändrats genom nya styrprinciper, som New Public Management, och deras konsekvenser i form av individualism och egenintressen av publicering (Macfarlane \& Cheng, 2008).

Begreppet intellektuell organisering är framför allt hämtat från Richard Whitleys $(1984 ; 2000)$ analyser av akademin i socialt och intellektuellt hänseende. Whitley menar att olika delar av akademin är organiserade på olika sätt, vilket är av central betydelse för dess verksamhet. Utifrån detta utvecklar han ett system av organisatoriska idealtyper för att precisera dessa olikheter (se Whitley, 1984, s. 158). Organiseringen är beroende av kontextuella förhållanden - av hur resurser fördelas inom olika områden och av vilka intressenter och adressater som verkar inom dessa områden. Intellektuell organisering kan studeras utifrån i vad mån forskarna inom ett vetenskapligt område erkänner och refererar till varandra, och med vilken säkerhet som viktiga forskningsuppgifter kan förväntas i ett visst kunskapsläge. 
Organiseringen av exempelvis fysik som vetenskap kännetecknas av att forskarna i stor utsträckning har gemensamma referenser och förutsägbara citeringar och erkännanden av kunskapsbidrag. Givet detta kan krav på forskning och bestämning av nya forskningsuppgifter förutses relativt väl. Inom fysik är kunskapsutvecklingen - åtminstone i grova drag - väl känd och kan följas i centrala tidskrifter. Vi kan förstå detta som ett koherent och centraliserat kunskapsområde kännetecknat av stor stabilitet. Fysik framstår därmed, enligt Whitleys terminologi, som "a conceptually integrated bureaucracy". Sådan organisering ses ofta som förebild inom akademin.

Men det kan i praktiken se annorlunda ut. Whitley menar exempelvis att företagsekonomi som ett område inom akademin har en helt annan form av organisering. Här erhålls resurser från många olika håll och det finns viktiga adressater med olika intressen. Här är också samstämmigheten i forskningsreferenser relativt låg och det är snarast omöjligt att förutse vilka forskningsuppgifter som behöver lösas. Whitley ser detta som "a fragmented adhocracy", som ett fragmenterat och löst strukturerat kunskapsområde svårt att överblicka med en rik variation av tidskrifter. ${ }^{2}$ Här ser vi två olika idealtyper i organiseringen av vetenskapligt områden - som en regelstyrd byråkrati eller som en löst organiserad och kontextuellt styrd adhocrati, eller som det benämns inom organisationsteori "adokrati" (se Mintzberg \& McHugh, 1985).

Lars Engwall (1995) har följt och analyserat det företagsekonomiska området och granskat dess utveckling. I sin forskningsgenomgång konstaterar han:

The analysis provides evidence, in full accord with Whitley's claim, that management studies are less integrated than disciplines such as mathematics, chemistry, the history of science and economics. However, there is also evidence that the degree of integration is increasing. (s. 225)

Engwall visar att företagsekonomi är relativt löst integrerat som område, men att integreringen i viss mån har ökat. Denna slutsats är särskilt intressant i relation till Whitleys (op.cit.) hävdande att föga kan hända med ämnets organisering givet rådande villkor, exempelvis finansiering, och adressater som forskningen riktar sig till.

Vi menar att organiseringen av företagsekonomi har många gemensamma drag med organiseringen av det pedagogiska kunskapsområdet - som flexibel och probleminriktad och starkt beroende av kontextuella förhållanden vilket $i$ sin tur kräver bevakningar av relevanta kontexter och en vaksam hantering av forskningens utveckling relativt vetenskapliga normer och bedömning av kunskapsbidrag. 


\section{OM STARTEN AV PEDAgOgISK ForSKNING I SVERIGE}

Tillkomsten av tidskriften för ett kvarts sekel sedan byggde till stor del på diskussioner förda inom Professorsmötet i pedagogik, samt i Beredningsgruppen för pedagogik vid det dåvarande HumanistiskSamhällsvetenskapliga Forskningsrådet (HSFR) som också behandlade didaktisk forskning. Vidare fördes diskussioner om behov av vetenskapliga tidskrifter $\mathrm{i}$ anknytning till reformeringen av skolväsendet och till lärares professionaliseringssträvanden. Vi ska börja med att ge en bild av detta läge.

En viktig anledning till att starta Pedagogisk Forskning i Sverige var det då rådande kommunikationsmönstret inom det pedagogiska kunskapsområdet som dominerades av institutionsrapporter, monografier och enstaka artiklar i vetenskapliga tidskrifter. ${ }^{3}$ Det förekom ganska lite av internationell vetenskaplig publicering och av internationellt uppmärksammade publikationer av svenska forskare. Detta märks i de uppgifter som kan erhållas från olika sökmaskiner som Web of Science, där det fortfarande under 1990talet var relativt få texter från Sverige som syntes på de internationella vetenskapliga arenorna. ${ }^{4}$ Problemet var alltså inte tillgång på tidskrifter eftersom det fanns gott om internationella vetenskapliga tidskrifter med olika slags inriktning (se Lindblad, Kyndel \& Larsson, 2004, s. 46 ff). Till detta kom att ett antal internationella forskarorganisationer med sina respektive tidskriften redan var verksamma med de möjligheter till publicering och kommunikation som där var för handen för forskare vid svenska lärosäten. Vi såg det därför som mindre viktigt att starta ytterligare en engelskspråkig tidskrift.

Ett ytterligare skäl för en svenskspråkig vetenskaplig tidskrift var behovet av texter för forskningsanknytning av pedagogiska utbildningar och lärarprofessionen. Detta skulle underlättas av att vetenskapliga texter var tillgängliga på svenska - att de kan användas i undervisningen för att lägga fram och pröva hållbarheten hos olika argument (se Björklund, 1991). Vidare ansåg vi att vi saknade sådana centrala och stabiliserade tidskrifter som förekom inom andra ämnen, som exempelvis Statsvetenskaplig Tidskrift ${ }^{5}$ för statsvetare och Sociologisk Forskning ${ }^{6}$ för sociologer.

Till bilden hör att i början av 1990-talet, när de genomgripande reformerna av förskola, grundskola och gymnasieskola började sätta sig, ökade lärarorganisationernas intresse av att få yrket betraktat som en profession. Sonderingar gjordes om det skulle vara möjligt att föra samman de olika fackföreningarna till en enda för att stärka den professionella framtoningen. Intresset för att knyta den professionella identiteten till vetenskapligt framtagen kunskap ökade som ett inslag i professionaliseringssträvandena. Den kunskap som den pedagogiska forskningen producerade, vilken skulle kunna vara användbar inom lärarprofessionerna, presenterades huvudsakligen som avhandlingar eller som institutionsrapporter. Den var föga tillgänglig för de många utövarna av läraryrkena. En tidskrift (Forskning om 
utbildning) publicerade forskningsartiklar på svenska och i en annan (Nordisk Pedagogik) fanns forskningsbidrag på skandinaviska språk att tillgå. Den statliga skoladministrationen gjordes om så att Skolöverstyrelsen 1991 ersattes av Skolverket. Inom det nya verket fanns en forskningsnämnd som fördelade medel för pedagogisk forskning men där också diskussioner fördes om hur forskning och vetenskapliga problem skulle kunna spridas och komma till användning. I en utredning som presenterades för denna nämnd 1992 (Ekholm, 1992) gjordes ett läse-experiment där forskares originaltexter och journalistiskt bearbetningar av samma texter sänts ut till skolor. Resultaten från dessa försök ledde till ett förslag till Skolverket om att tidskriften Forskning om utbildning skulle stärkas och att en mer journalistisk tidskrift skulle ges ut av Skolverket där forskning presenterades. Detta förslag lades åt sidan och istället engagerade sig Skolverket $\mathrm{i}$ tidskriften Praxis som inriktades på upplysning om forskning och på debatt om utbildningsfrågor. Den satsningen innebar i praktiken att ingen inhemsk tidskrift fanns för forskare att publicera sig i under mitten av 1990-talet. Lärarförbundet, som strävade vidare mot att få yrket betraktat som en profession, tog då initiativet att 1996 ge ut en tidskrift (Pedagogiska Magasinet) som skulle vara en mötesplats mellan verksamma pedagoger, forskare och beslutsfattare där pedagogisk forskning var huvudinnehållet.

I en inledande artikel i det första numret av Pedagogisk Forskning i Sverige skrev vi (Ekholm \& Lindblad, 1996) att tidskriften ska vara inomvetenskaplig och pluralistisk, inte ägd av någon eller några traditioner eller driva något särskilt intresse:

Pedagogisk Forskning i Sverige är en tidskrift av pedagogiska forskare för pedagogiska forskare samt för dem som önskar sätta sig in i den pedagogiska forskningen i Sverige med dess olika traditioner. Poängen med tidskriften är att den ska vara inomvetenskaplig. I artiklar, recensioner, och översikter ska man möta pedagogisk forskning i dess olika skepnader. Vidare skall den vara pluralistisk - olika traditioner och ståndpunkter skall komma fram $\mathrm{i}$ innehållet. (s. 5)

Vi ansåg vidare att en sådan svenskspråkig tidskrift skulle vara av betydelse för olika pedagogiska utbildningar och deras forskningsanknytning:

Avsikten med denna inomvetenskapliga tidskrift är då samtidigt att tjäna syftet att hjälpa lärare vid universitet och högskolor och deras studerande att få en gripbar översikt och en aktuell kontakt med forskningen inom det pedagogiska fältet. (s. 5)

En sådan tidskrift skulle bygga på professionella normer vad gäller ägande, redaktionell verksamhet, och offentliga diskussioner rörande dess verksamhet, enligt Ekholm och Lindblad (op.cit.): 
För det första är den inte privat eller enskild. Den skall "ägas" av professionen - av forskarna själva. För det andra ska frågor om redaktion och redaktionsarbete, om kvalitet och täckning bestämmas av forskarna som kollektiv. För det tredje ska diskussioner om tidskriftens inriktning och uppläggning vara föremål för en offentlig debatt i forskarsamhället.

På så sätt hade man förhoppningen att tidskriften skulle bidra till en utveckling av det pedagogiska kunskapsområdet, vilket också rimmade väl med forskningsetiska principer á la CUDOS:

Genom det kollektiva "ägandet" och den offentliga diskussionen om tidskriften blir den en gemensam angelägenhet för forskningen och bidrar till att göra ämnets identitet mer tydlig och att höja kvaliteten på forskningen. Samtidigt ökar medvetenheten om olika traditioner och ståndpunkter inom ämnet. (s. 6)

Tidskriften fick sin första hemvist i Göteborg. Organisatoriskt byggde den på att ett antal institutioner tecknade sig som prenumeranter. Dessa institutioner fick tidskriften till sina medarbetare. Biörn Hasselgren utsågs till redaktör, Daniel Kallós till ansvarig utgivare och ett redaktionsråd utsågs med medlemmar från olika lärosäten. Därmed hade tidskriften Pedagogisk Forskning i Sverige startat.

\section{REDAKTIONSSKIFTEN OCH SWERA SOM ORGANISATORISK BAS FÖR TIDSKRIFTEN}

När det sedan blev dags för redaktionsskifte fick Lisbeth Lundahl, Biörn Hasselgren och Sverker Lindblad i uppdrag av professorsmötet att genomföra det. Vi såg det som en möjlighet att öka transparensen i vår tidskrifts sätt att verka genom att finna vägar att inbjuda de som var intresserade att anmäla sitt intresse och att organisera huvudmannaskapet för tidskriften så att den blev föremål för granskning och diskussion inom forskarsamhället i stort. Lund/Malmö fick först uppdraget med Bosse Bergstedt som redaktör, och nu är den placerad vid Linnéuniversitet med Daniel Sundberg vid rodret. Till saken hör nu också att Pedagogisk forskning i Sveriges (PfS) portal förhoppningsvis håller på att utvecklas till en ny del i organiseringen av det pedagogiska kunskapsområdet. ${ }^{7}$ Här hanteras olika frågor och utvecklas resurser, exempelvis för rekrytering och olika typer av bedömningar. Och detta menar vi är betydelsefullt för framtiden!

Med det kollektiva ägandet, organiserade redaktionsskiften och krav på transparens som ambition för Pedagogisk forskning i Sverige startade vi SWERA. Det var därvid viktigt för oss att inte konkurrera med Nordisk 
Förening för Pedagogisk Forskning (NFPF/NERA). I fokus för SWERA sattes den intellektuella och sociala organiseringen av det pedagogiska kunskapsområdet på kollegial grund. Råd, gemensamma rådslag och seminarier skulle därvid vara grundelement i SWERA istället för paperpresentationer och föreläsningar. Denna organisering innebar att Pedagogisk Forskning i Sverige med sina verksamhetsberättelser och verksamhetsplaneringar blev en viktig punkt i SWERAs årliga möten. Samtidigt sattes en viktig princip att SWERAs styrelse inte ska lägga sig i det redaktionella arbetet med tidskriften.

\section{OM MOTTAGANDET AV TIDSKRIFTEN I FORSKARSAMHÄLLET}

Avsikten med denna artikel är inte att göra en utvärdering av tidskriften. Men det kan vara intressant att få en bild av hur tidskriften har tagits emot och utnyttjats.

Ett tidigt uttryck för hur tidskriften har fungerat står att finna i den utvärdering som dåvarande HSFR lät Kjell Härnqvist (2001) göra. Härnqvist menar att tidskriften förtjänar rådets stöd och summerar sin genomgång som följer:

De tryckta bidragen är av god kvalitet. De olika tidskriftshäftena är välkomponerade och har en tilltalande typografi. Deras innehåll kan även nås på web-sidor som är mycket välbesökta. Artiklarna har stor spridning över olika områden av pedagogikens fält. Betoningen av teori och diskussion är stark. De empiriska undersökningar som redovisas har en markant övervikt för kvalitativa analyser, vilket torde vara karakteristiskt för nuläget inom svensk pedagogikforskning. Tillsammans ger dessa drag tidskriften en profil som skiljer sig klart från andra nordiska tidskrifter inom pedagogik - inte minst genom att på meta-nivå behandla pedagogikforskningens förutsättningar och betingelser. (a.a., s. 220)

Senare bedömningar stödjer Härnqvists bild. Sålunda gjorde exempelvis Hansen och Lindblad (2010) en genomgång av utbildningsvetenskaplig publicering och kommunikation på uppdrag av VR. De fann där att Pedagogisk Forskning i Sverige var bland de mest brukade vetenskapliga tidskrifterna av forskare vid de lärosäten som undersöktes. ${ }^{8}$ De såg också att den var relativt väl citerad jämfört med andra tidskrifter inom området. Samtidigt visade det sig att ett fragmenterat svenskt publiceringsmönster var för handen inom det pedagogiska kunskapsområdet. Inom det mycket stora antalet tidskrifter förekom endast enstaka bidrag från Sverige och åtskilliga artiklar var sällan eller aldrig citerade.

Ännu lite senare gjorde den tillträdande redaktionssekreteraren Anders Olsson en tillbakablick på tidskriften när Lund/Malmö övertog redaktionen 
2012. Olson tog därvid upp frågor om tvärvetenskap och disciplinärt samarbete och betydelsen av detta för tidskriften (Olsson, 2012). Att hantera dessa frågor är av vital betydelse för det pedagogiska kunskapsområdet och då även för vår gemensamma tidskrift.

Ytterligare en undersökning - fast nu 2021 och av enkelt slag - genomförde vi med hjälp av sökmaskinen "Publish or Perish". ${ }^{9}$ Vi fann med denna sökmaskin 635 artiklar publicerade i tidskriften som sammanlagt har citerats 11550 gånger. Mycket citerade artiklar behandlar barnpedagogiska och specialpedagogiska frågor, samt ramfaktorteoretiska modeller och sociokulturella perspektiv. Tidskriften har alltså en rejäl bredd och används mycket, efter vad vi kunnat finna.

Sammanfattningsvis drar vi slutsatsen att tidskriften tagits väl emot av forskarsamhället; den användes och brukas inom det pedagogiska kunskapsområdet och åtskilliga artiklar, skrivna inom ramen för olika forskningstraditioner, har haft rejäl genomslagskraft. Kort sagt kan vi se utvecklingen av Pedagogisk Forskning i Sverige som något av en framgångssaga relativt de förhoppningar vi hade för ett kvarts sekel sedan!

\section{TIDSKRIFTEN PEDAGOGISK FORSKNING I SVERIGE I ETT FÖRÄNDRAT SYSTEM FÖR HÖGRE UTBILDNING OCH FORSKNING}

Starten av Pedagogisk Forskning i Sverige byggde på försök att agera så förnuftigt som möjligt $i$ termer av vad som var vetenskapligt vettigt och strategiskt möjligt vid den tiden. Men det var för tjugofem år sedan. Sedan dess har organiseringen inom det pedagogiska kunskapsområdet förändrats, liksom dess omvärld, exempelvis i styrningen av högre utbildning och forskning, samt vilken betydelse tidskrifter och publicering har därvidlag. Här kommer några punkter som vi menar är av betydelse:

Publiceringsmönstret är idag mycket annorlunda. Institutionsrapporter har minskat avsevärt i såväl omfattning som betydelse. Doktorsavhandlingar är ofta sammanläggningar av artiklar i vetenskapliga tidskrifter och publicering $i$ internationella vetenskapliga tidskrifter har ökat markant! Likaså har deltagande i nationella och internationella konferenser och forskningsnätverk ökat och då också produktion av såväl papers som bidrag till antologier. På så sätt har det pedagogiska kunskapsområdet förändrats i vad många ser som en önskvärd riktning vad gäller publicering och internationellt samarbete. Pedagogisk Forskning i Sverige är en del av denna tendens, efter vad som framkommit ovan.

Efter vad vi noterat ser det emellertid inte lika bra ut vid en närmare granskning av hur forskningskommunikationen fungerar inom det pedagogiska kunskapsområdet. Åtskilliga artiklar publicerade av forskning inom området uppmärksammas inte av andra forskare och lärare, läses inte, 
eller öppnas rentav inte för läsning överhuvudtaget, även om dessa artiklar som sådana kan anses vara av mycket bra kvalitet (Lindblad, 2015). ${ }^{10}$ Till bilden hör också, enligt vår bedömning, att ömsesidigt refererande och erkännande av kunskapsbidrag ofta är bristfälliga, liksom att val av tidskrifter för publicering ibland förefaller slumpmässiga (bortsett från några mer centrala tidskrifter som presenterades tidigare). Det är inte orimligt att den ökade mängden tidskrifter bidragit till detta (jfr Sile \& Vanderstraeten, 2019). Vidare har det också dykt upp tidskrifter av tvivelaktig inriktning, såsom så kallade svarta tidskrifter utan kvalitetsgranskning och med ekonomisk vinst som främsta intresse. Dessa drar också till sig författare från Sverige som på så sätt kan fördärva både för sig själv och för andra. ${ }^{11}$ Givet sådana iakttagelser framstår forskningskommunikationen inom det pedagogiska kunskapsområdet som alltmer fragmenterad och med ökat behov av organisering av kunskapsbidrag. Motsvarande tendenser gör sig veterligen gällande även inom andra områden av akademin - men här avhandlas det pedagogiska kunskapsområdet.

En förklaring till denna förändring kan vara tillvägagångssätt vid rekrytering till olika positioner och styrningen av resurser efter resultat inom akademin där enskilda publikationer är av betydelse som sådana, och inte deras eventuella kunskapsbidrag (se exempelvis Haake \& Silander, 2021). På så sätt åstadkoms tendenser $\mathrm{i}$ form av akademisk drift, från publicering $\mathrm{i}$ termer av gemensamma kunskapsbidrag, till publicering för egenintressen institutionellt och individuellt - ofta i strid med etiska normer för vetenskaplig verksamhet och med tveksamt värde för vetenskaplig utveckling.

Vad som också har skett är att kraven på och förutsättningarna för kunskapsproduktion förändrats inom det pedagogiska kunskapsområdet, dels genom tillkomsten av utbildningsvetenskapliga forskningsfinansiärer, dels genom att olika ämnen nu utvecklas inom området och samtidigt kräver såväl erkännande som finansiering. Detta sker samtidigt som antalet forskare ökat liksom behovet av pedagogiska utbildningar.

\section{SLUTSATSER ATT DISKUTERA}

Utifrån denna korta genomgång kan vi se att det pedagogiska kunskapsområdet förändrats rejält under det kvartssekel som förlupit sedan starten:

- Publiceringsmönstret har förändrats med starkt ökad publicering i ett mycket större antal vetenskapliga tidskrifter. Kommunikationsmönstret framstår som mer fragmenterat genom bruket av ökat antal tidskrifter med olika inriktning och adressater och genom att forskningssamarbete äger rum i ett större antal forskningsnätverk. Innehållsligt förefaller refererandet ofta vara osäkert hanterat och bygga på personliga preferenser och tillfälligheter. 
- Pressen på publicering har ökat som ett led i hur karriärer formas inom en trängre akademi och genom förändrade principer för resursfördelning inom systemet för högre utbildning och forskning. Detta kan i sin tur innebära att dynamiken inom det pedagogiska kunskapsområdet förändras i termer av ökad konkurrens och individuella intressen av publiceringar.

Den bild som växer fram för oss är en desorganisering av kunskapsområdet som förefaller gå på tvärs mot de normer för vetenskaplig verksamhet som låg till grund för skapandet av Pedagogisk Forskning i Sverige. Även om tidskriften som sådan varit framgångsrik så har problemen hopat sig vad gäller publicering och kommunikation inom området. Detta förstärks av den kritik, om än på mer eller mindre lös grund, som förs fram mot den forskning som bedrivits, exempelvis i massmedia. ${ }^{12}$

Frågan blir då också vilken vidare betydelse dessa tendenser inom publicering och kommunikation har för forskningsanknytningen av pedagogiska utbildningar och för kvaliteten i det vetenskapliga engagemanget av forskning inom skola och utbildning. Med detta för ögonen kan det vara vettigt att lyfta fram den distinktion Sverker Gustavsson gör mellan uppslag och bevis vad gäller vetenskapligt engagemang och objektivitet relativt samhällsfrågor och det därmed sammanhängande kravet på kunskapens organisering (Gustavsson, 2010).

Konsten ligger $\mathrm{i}$ att kunna kombinera vetenskaplig intuition och påhittighet med en förmåga att bevisa. Bra bevisning hjälper föga om det som bevisas är ointressant. Omvänt räcker det inte med lysande uppslag. Framgångsrika studier förutsätter en förening av bra frågor och trovärdiga svar. (s. 4)

För att åstadkomma en sådan förening av bra frågor och trovärdiga svar krävs en social organisering av forskning och forskningskommunikation. Enskilda uppslag räcker inte heller inom det pedagogiska kunskapsområdet vare sig för forskning eller för forskningsanknytning. Vad som krävs är gemensamt arbete för att diskutera och pröva eventuella kunskapsbidrag. Med denna utgångspunkt blir det särskilt viktigt att analysera organiseringen av det pedagogiska kunskapsområdet och vad denna organisering bygger på för förutsättningar och praktiker. Detta krävs för att i ordnade samtal pröva de argument som förs fram, för att identifiera vad som är viktiga frågor och vad som kan vara trovärdiga svar på dessa frågor. Av detta följer inte krav på konsensus, men väl kringsyn och insikt i styrkor och svagheter hos olika forskningspositioner i systematiska diskussioner i enlighet med vetenskapliga normer (som hos Merton, 1973). 
Med denna problematik för ögonen är det en vital uppgift idag att bidra till en intellektuell och social organisering inom det pedagogiska kunskapsområdet. Vad blir innebörden av detta för vetenskaplig publicering och kommunikation? Hur går vi vidare från publicering av intressanta uppslag och fokusering på forskningsuppgifter till mer integrerade kommunikationsmönster, utan att för den skull lägga hämsko på enskilda forskningsintressen? Och hur ska vi utveckla en verksamhet som svarar upp mot vetenskapliga normer och samtidigt svarar mot olika aktörers intressen och professionella behov av objektiv kunskap?

Det finns inte några enkla svar på sådana frågor - men de behöver hanteras av forskarsamhället på ett systematiskt och eftertänksamt sätt som en del av verksamheten inom det pedagogiska kunskapsområdet och dess omvärld. Det är vår förhoppning att Pedagogisk Forskning i Sverige kan verka för en sådan intellektuell och social organisering!

\section{NOTER}

${ }^{1}$ Se t. ex analyser med olika inriktning som Lagemann (2000), Gross \& Keiner (2020) eller EERJ specialnummer 2002, nr 1 med bidrag från olika europeiska kontexter.

${ }^{2}$ Adhocracy kan översättas till adokrati och ses snarast som motsatsen till byråkrati. Det definieras på följande sätt: An organizational system designed to be flexible and responsive to the needs of the moment rather than excessively bureaucratic.

Adhocracy is a structureless organization used to solve various problems. It is a type of organization that operates in opposite fashion to a bureaucracy.

https://www.definitions.net/definition/adhocracy?source=agave

3 Termen "pedagogiskt kunskapsområde" tillkom senare. För 25 år sedan var "pedagogik och didaktik" den dominarande beteckningen (jfr Rosengren och Öhngren, 1997). Senare har termer som "pedagogiskt arbete", "praktiknära forskning" och "utbildningsvetenskap", liksom ett antal forskarutbildningsämnen (se Wärvik et al, 2019)

${ }^{4}$ Enligt Web of Science (utifrån den enkla sökningen EDUC* analyserad över land) återfanns 0 publikationer från Sverige 1960 i deras data, 5 st år 1990, och med ökningar efterhand till 189 träffar i WoS 2010 och till 682 st år 2020. Motsvarande resultatbild erhålles vid sökningar med andra breda söktermer som LEARN* OCH TEACH*. Det är först en bit in på 2000-talet som svensk forskning börjar bli synlig i någon större utsträckning. Enstaka forskare som Ference Marton, Ingrid Pramling Samuelsson och Anders Jonson är dock uppmärksammade tidigare, enligt denna sökning

${ }^{5}$ https://statsvetenskapligtidskrift.org/

${ }^{6}$ https://www.sociologiskforskning.se/

${ }^{7}$ https://pedagogiskforskning.se/

8 'De fem mest brukade tidskrifterna var i tur och ordning: Scandinavian Journal of Educational Research, Pedagogisk forskning i Sverige, Tidskrift för lärarutbildning och forskning, European Educational Research Journal, Scandinavian Journal of 
Psychology, Nordisk pedagogik - Nordic Studies in Education. Se Hansen \& Lindblad, 2010.

${ }^{9}$ Harzing's Publish or Perish. Sökning 20-06-21 Publication Name "Pedagogisk Forskning i Sverige". Google Scholar search.

${ }^{10}$ Se också de utvärderingar som gjorts av svenska lärosäten som Göteborg (2010; 2019) och Uppsala (2004 och 2011).

11 SWERAs tidskriftsråd har ägnat stor uppmärksamhet åt denna fråga.

12 Se exempelvis de genomgångar som Lindblad (2020) och Lundahl (2020) gjort av dagspressen.

\section{REFERENSER}

Björklund, Stefan (1991). Forskningsanknytning genom disputation. Uppsala Universitet.

Ekholm, Mats (1992). Information om forskning och forskningsresultat. Arbets-PM inom Skolverkets forskningsnämnd. Skolverket.

Ekholm, Mats, \& Lindblad, Sverker (1996). På väg mot en svensk pedagogisk tidskrift. Pedagogisk. Forskning i Sverige, 1(1), 1-7.

Engwall, Lars (1995). Management research: A fragmented adhocracy?. Scandinavian Journal of Management, 11(3), 225-235.

Gross, Barbara, \& Keiner, Edwin (2020). Intercultural Education and Educational Research in a Globalizing World: Historical Developments and Contemporary Challenges. Ricerche Pedagogiche, 54(214), 27-52.

Gustavsson, Sverker (2010): Engagemang och vetenskap. I Matilda Hald (red.), Över gränserna (s. 84-92). Cemus - Centrum för miljö- och utvecklingsstudier, Uppsala.

Haake, Ulrika, \& Silander, Charlotte (2021). Excellence seekers, pragmatists, or sceptics: Ways of applying performance-based research funding systems at new universities and university colleges in Sweden. European Journal of Education, 56, 307-324. https://doi.org/10.1111/ejed.12450

Hansen, Michael, \& Lindblad, Sverker (2010). Forskningskommunikation och publiceringsmönster inom utbildningsvetenskap: En studie av svensk utbildningsvetenskaplig forskning vid tre lärosäten (Vetenskapsrådets Rapportserie Nr 10:2010). Vetenskapsrådet.

Härnqvist, Kjell (2001). En granskning av tidskriften Pedagogisk Forskning i Sverige. Pedagogisk Forskning i Sverige, 6(3), 218-220.

Lagemann, Ellen C. (2000). An Elusive Science: The Troubling History of Education Research. The University of Chicago Press. 
Leydesdorff, Loet (2007). Scientific Communication and Cognitive Codification: Social Systems Theory and the Sociology of Scientific Knowledge. European Journal of Social Theory, 10(3), 375-388.

Lindblad, Sverker (2015). On organizing educational research communication in Europe: Past experiences and possible futures. European Educational Research Journal, 14(1), 30-34.

Lindblad, Sverker, Kyndel, Dag, \& Larson, Lena (2004). Internationella arenor för utbildningsveten skaper: om forskarorganisationer, vetenskapliga tidskrifter och överstatliga organisationer (Vetenskapsrådets rapportserie, 2004:5).

Vetenskapsrådet.

Lindblad, Sverker (2020): Om den politiska kritiken av forskning inom det pedagogiska kunskapsområdet. En studie av inlägg i svensk dags-press. Underlag till SWERA-seminarium 7-8 oktober 2020

Lundahl, Lisbeth (2020): Lärarutbildningens vedersakare. Underlag till SWERAseminarium 7-8 oktober 2020

Macfarlane, Bruce, \& Ming Cheng (2008). Communism, Universalism and Disinterestedness: Re-examining Contemporary Support among Academics for Merton's Scientific Norms. Journal of Academic Ethics, 6, 67-78.

Merton, Robert K. (1973) [1942]. The Normative Structure of Science. I Robert K. Merton, The Sociology of Science: Theoretical and Empirical Investigations (s. 267-278). University of Chicago Press.

Mintzberg, Henry, \& McHugh, Alexandra (1985). Strategy formation in an adhocracy. Administrative science quarterly, 30(2), 160-197.

Mitroff, Ian (1974). Norms in a Select Group of the Apollo Moon Scientists: A Case Study of the Ambivalence of Scientists. American Sociological Review, 39(4), 579-595.

Olsson, Anders (2012). Tidskriften Pedagogik Forskning i Sverige: Tillbakablick och lägesbeskrivning. Pedagogisk forskning i Sverige, 17(3-4), 145-151.

Rosengren, Karl E., \& Öhngren, Bo (Red.) (1997). An evaluation of Swedish Research in Education. HSFR.

Sīle, Linda, \& Vanderstraeten, Raf (2019). Measuring changes in publication patterns in a context of performance-based research funding systems: the case of educational research in the University of Gothenburg (2005-2014). Scientometrics, 118(1), 71-91.

Whitley, Richard (1984). The development of management studies as a fragmented adhocracy. Social Science Information, 23(4-5), 775-818.

Whitley, Richard (2000). The Intellectual and Social Organization of the Sciences. Oxford University Press.

Wärvik, Gun-Britt, Runesdotter, Caroline, \& Pettersson, Daniel (2019). Coproduction of knowledge on the educational Agora: Media activities and 'logics'. I 
Christina Elde Mølstad, \& Daniel Pettersson (red.), New Practices of Comparison, Quantification and Expertise in Education (s. 145-158). Routledge. 